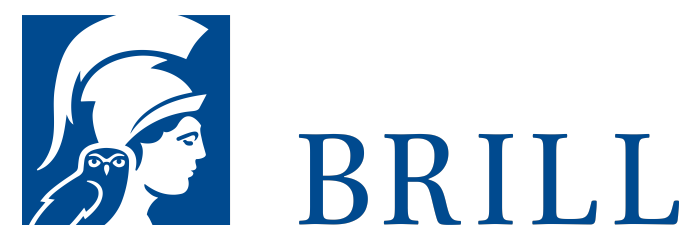

\title{
Grundkurs Informelle Logik
}

Begründen und Argumentieren im Alltag und in den Wissenschaften überSetzt von Thomas Keutner

Author: Christopher W. Tindale

Der Gegenstand der Informellen Logik ist das Hervorbringen, die Analyse und die Kritik von Begründungen und Argumenten im Alltag und in den Wissenschaften. Hierfür bedient sie sich eines Instrumentariums, das nicht nur der klassischen Schlusslehre, sondern ebenso auch der Rhetorik und Argumentationslehre entstammt. Daher liefert sie sowohl eine Lehre der Schlüsse und Fehlschlüsse, als auch eine Charakterisierung des Argumentierenden und seines Auditoriums. Das Werkzeug der Informellen Logik wird vorgeführt am Beispiel von Techniken zur Identifizierung von Thesen, Begründungen und Argumenten. Eine Betrachtung der Unterscheidungskriterien guter und schlechter Argumente erlaubt sodann die Bewertung von Begründungen wie auch die Produktion starker eigener Argumente. Eine paradigmatische Analyse gesellschaftlich-politischer und wissenschaftlicher Argumentationstypen und -strategien veranschaulicht den weiten Anwendungsbereich der Informellen Logik. Jedem Kapitel sind zahlreiche Übungsaufgaben angehängt, den Abschluss dieser Einführung bildet die Analyse eines Fallbeispiels für politisches Argumentieren und stellt so eine Zusammenführung der zuvor präsentierten Instrumente dar.

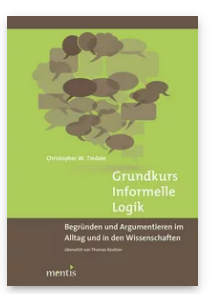

Pages: 195

Seiten

Language:

German

Subjects:

General, Philosophy

Publisher: Brill | mentis

E-Book (PDF)

Released online:

o1 Jul 2013

ISBN: 978-3-

89785-973-9

List price

Paperback

Publication date:

o1 Jul 2013

ISBN: 978-3-

89785-822-O

List price 
For more information see brill.com

Order information: Order online at brill.com +44330 333 0049 | customerservices@brill.com Submission information: brill.com/authors

Titles published by Brill | Fink, Brill | mentis or Brill | Schöningh: +49(o)715413279216| brill@brocom.de 